\title{
O comportamento do consumidor tecnológico diante dos valores ecologicamente corretos: ideologia verde versus responsabilidade social
}

\author{
Marina Nascimento Lemos Barboza* \\ Emílio J.Montero Arruda Filho**
}

\section{Resumo}

Este artigo apresenta uma análise da percepção de consumidores tecnológicos, diante dos novos produtos que integram o fator ecológico no Brasil. Por ser um conceito novo e pouco explorado, verifica-se a importância de um estudo sobre a ideologia e a responsabilidade social, inserida no discurso usado pelos usuários de alta tecnologia (celular, netbook e outros dispositivos). Com isto, foi realizada uma pesquisa de cunho qualitativo feita com consumidores, utilizando a netnografia como método, que consiste na extração de informações dos blogs/sites de discussões sobre o argumento pesquisado, para a decodificação e categorização dos grupos participantes desse tema. A pesquisa teve como resultado seis categorias de consumidores identificados, com subcategorias implícitas destes, dado os produtos integrados verdes. Baseados nisto, os profissionais de marketing podem utilizar desta compreensão quando lançarem produtos e no desenvolvimento de novos dispositivos, para objetivar maior percepção de valores de mercado e promoções dentre outros, para melhor entender o público alvo e sua preferência de consumo. Palavras-chave: Comportamento do consumidor. Inovação. Tecnologia. Produtos Verdes.

\footnotetext{
" Bolsista do Núcleo de Pesquisas e Estudos Socioeconômicos - Programa de Mestrado em Administração na Universidade da Amazônia (UNAMA.), Belém, PA, Brasil. E-mail: marina.nascimento3@gmail.com.

** Professor e investigador do Núcleo de Pesquisas e Estudos Socioeconômicos, Programa de Mestrado em Administração da Universidade da Amazônia (UNAMA), Belém, PA, Brasil. Doutor em Marketing para Estratégia de Empresas pela Università Degli Studi di Bergamo (Italia). Graduado em Engenharia Elétrica pela Universidade Federal do Pará (1995) e mestre em Engenharia Elétrica pela mesma Universidade (1998).E-mail: emilio.arruda@unama.br.
} 


\section{Technological consumer's behavior in the face of values 'environmentally friendly': green ideology versus social responsibility}

\section{Abstract}

The present article intends to show a brief analysis about the technological consumer's perception concerning the new products which integrates the ecological factor in Brazil. For being a new concept and hardly explored, we are able to perceive the importance of studying about ideology and social responsibility in the discourse used by users of high-tech devices (cellphones, netbooks and others). Therefore, a qualitative research was perfomed with Brazilian consumers using netnography as a method, wich consists in the extraction of reports about the explored theme from specialized blogs/websites, in order to decode and categorize the groups that take part in this subject. The research resulted in six differents categories of known consumers, exposing some implied subcategories according to the green products integrated. Based on that, marketing professionals may use this comprehension when intending to launch new products and develop new devices, aiming to increase the perception of market values, sales, among others, to better understand the target audience and their consumer's preferences.

Keywords: Consumer's Behavior. Innovation. Technology. Green Products.

\section{El comportamiento del consumidor y los valores tecnológicos 'ecológicamente correctos': la ideología verde versus con la responsabilidad social}

\section{Resumen}

Este artículo presenta un análisis de percepción de consumidores tecnológicos, delante los nuevos productos que integran el factor tecnológico en Brasil. Siendo un concepto nuevo y poco desarrollado, se verifica la importancia de un estudio sobre la ideología y la responsabilidad social, inserida en el discurso usado por usuarios de alta tecnología (móviles, netbook y otros dispositivos). Con eso, una pesquisa de rasgo cualitativo fue realizada con consumidores brasileños, utilizando la netnografia como método, que consiste en la extracción de informaciones de blogs/sitios de discusiones sobre el argumento pesquisado, para la decodificación y categorización de los grupos participantes de este tema. La pesquisa ha tenido como resultado seis categorías de consumidores identificados, con subcategorias implícitas de ellos, dados los productos integrados verdes. En base a esto, los profesionales de marketing pueden utilizarse de esta comprehensión cuando quieran lanzar nuevos productos y en el desarrollo de nuevos dispositivos, objetivando mayor percepción de valores de mercado y promociones, entre otros, para entender mejor al público target y su preferencia de consumo.

Palabras clave: Comportamiento del consumidor. Innovación. Tecnología. Productos ecológicos. 


\section{Introdução}

$\mathrm{D}$ esde a revolução industrial, a sociedade presencia um grande crescimento das indústrias de bens e serviços, gerando grandes transformações socioeconômicas e ambientais. A sociedade atual testemunha grandes alterações no meio ambiente, que fez com que a partir da década de 60 as pessoas passassem a refletir sobre as consequências do desenvolvimento das atividades industriais, buscando formas de impor limites às indústrias, para que as mesmas não causassem danos irreparáveis aos recursos físicos e humanos da Terra (SANCHES, 2000).

A alternativa imposta ao mercado na preferência de consumo por "produtos verdes" (PORTILHO, 2004; BEDANTE, 2004) e tecnológicos (celular, netbook e outros dispositivos), demonstra uma participação cidadã, além do aumento da consciência ambiental em torno deste argumento. O consumidor verde ao fazer uma compra, leva em consideração não só os critérios básicos de preço e qualidade, mas também procura o nível ecologicamente correto ou sustentável de um produto (BERTOLINI; POSSAMAI, 2005).

O mercado, no decorrer dos últimos anos, apoiou-se em produtos de alta tecnologia, com itens não somente utilitários voltados para o trabalho e o estudo, mas também, com itens agregados com hedonismo, voltados para o prazer e diversão (OKADA, 2005). Sendo assim, este artigo apresenta a relação entre os fatores de preferência de uso, valor, benefícios e identidade, dentre outros sobre o comportamento, para análise de marketing deste consumo tecnológico. Um dos pontos fundamentais discutido apresenta-se como o uso hedônico / utilitário dos "produtos verdes" sendo um importante diferencial, para posicionar e sinalizar a escolha de consumo (decisão e satisfação), a qual pode ser valorizada pela percepção do produto posicionado como um produto da moda (fashion) (KATZ; SUGIYAMA, 2006).

Logo, com esta era da informação desenvolvida pelo advento da internet, muitas informações sobre benefícios e malefícios dos produtos são difundidas pelas chamadas mídias colaborativas. As redes sociais e grupos de discussão são agentes que ajudam os consumidores indecisos, fornecendo todas as características intrínsecas 
dos produtos (STEPHEN; TOUBIA, 2010). Com isto, este artigo faz uma análise da percepção de consumidores tecnológicos diante dos novos produtos que interam o fator ecológico interpretando quais valores diferenciam este produto e se o uso ou compra deste, é determinado por valores utilitários ou hedônicos / sociais.

$\mathrm{O}$ artigo desenvolve uma pesquisa exploratória de cunho qualitativo que pretende analisar o comportamento do consumidor e suas preferências, utilizando inicialmente o método de análise pela netnografia uma forma de coleta de dados, que consiste em buscar informações de blogs/fóruns de discussões (KOZINETS, 2002).

\section{Comportamento do consumidor de produtos tecnológicos}

No mercado de convergência tecnológica, há constantemente mudanças e novas necessidades de políticas, difusões, inovações e demandas, a ponto de quase sempre modificar e moldar o comportamento do consumidor diante as novas inserções mercadológicas. O processo de difusão da inovação ocorre na medida em que as comunicações são transmitidas com novas ideias para o mercado (ROGERS, 2003). Quando bem difundido e experimentado, o produto é adotado ou rejeitado refletindo em mudanças sociais e mercadológicas correntes.

A grande oportunidade de negócios no mercado convergente não foi a criação de serviços diferentes em um sistema ou dispositivo, mas inserir muitos destes serviços conjuntamente (KIM et al., 2005). Os produtos all-in-one (tudo em um só) invadiram o mercado (NUNES; WILSON; KAMBIL, 2000), no qual novos equipamentos (smartphones - telefones inteligentes, netbooks - novo substituto para o notebook) e novos conceitos que surgem a cada dia, são lançados possuindo integrações do tipo vídeo-câmera, plataforma mp4, música com mp3, conexão de internet, acessos a e-mails e descarregamento (download) de programas, músicas e serviços, todos inseridos em um único dispositivo simultaneamente (FUNK, 2004).

Os consumidores têm a ilusão de que quanto maior o número dessas integrações dentro de um produto ou dispositivo, maior será o uso (NUNES; WILSON; KAMBIL; 2000; HARRIS; BLAIR, 
2006). Porém, o fato de possuir muitas utilidades no mesmo produto aumentou a dificuldade de manuseio, visto que, não houve uma experiência anterior sobre o uso de cada serviço separado ou em conjunto (NUNES, 2000). Em certo ponto o consumidor acaba se confundindo em relação às experiências anteriores, dado seus conhecimentos verdadeiros sobre o produto (HOCH; DEIGHTON, 2002) e gerando uma falta de habilidade, para explorar os benefícios da disponibilidade convergente nestes.

Os consumidores geralmente não fazem uma predição bem definida, sobre o uso de um novo produto pelo custo e benefício devido às novas integrações. Segundo Dahl e Hoeffler (2004), essa dificuldade de predição do beneficio se dá pelo problema em fazer a auto-referência, ou seja, para os consumidores se verem usando tal produto de forma que descreva exatamente o seu eu. É como se fossem partes de sua identidade, nas quais "estes objetos externos que consideramos como parte de nós, compreende o eu estendido" (BELK, 1988; SOLOMON, 2008). Sendo assim, o design do produto pode garantir ao usuário moda e a beleza, como um diferencial pelo fator social que este representa, quer seja para demonstrar poder ou ter um prestígio social.

Como a moda é um dos motivos na decisão de compra desses produtos, esta é uma forma que o consumidor encontrou de apresentar seu desejo interior. Assim, analisando contextos atuais, um celular, por exemplo, é usado mais como um acessório de utilidade social do que como sua função principal que é realizar chamadas (KATZ; SUGIYAMA, 2006).

Então, seguindo estes estudos de necessidade e desejo, identifica-se na literatura de marketing que a palavra hedonismo, relaciona-se ao uso de produtos tecnológicos, quando identifica o prazer, o divertimento e a satisfação com o uso ou possessão do produto, quer este seja verde ou não, o valor na compra do produto está direcionado para os atributos que gerem percepção hedônica e valor social, ao invés de benefícios utilitários. A mensuração agora é relacionada com o que o consumidor hedônico deseja ou prefere, como um produto normal que traga prazer ou um produto sustentável / verde que traga prazer e status social pela preferência ecológica. 
Logo, sabe-se que ao longo do estudo que envolve o comportamento do consumidor, os usuários preferem bens hedônicos com a intenção de lhe proporcionar prazer e diversão. Todavia, possuem necessidade pelos aspectos utilitários para melhor justificarem a compra hedônica, devido ao sentimento de culpa que esta compra gera (OKADA, 2005; DAHL; HONEA; MANCHANDA, 2005).

Segundo Arruda Filho (2008), o consumo de produtos tecnológicos que possuem fatores ligados ao hedonismo, pode transformar-se em utilidade social percebida, que passa a ser determinante para o prestígio social de cada indivíduo, quando este possui o prazer relacionado ao compartilhamento social do divertimento. Utilidade percebida é definida como: o grau de que uma pessoa acredita que utilizar um determinado sistema, aumentaria seu desempenho ou diminuiria seu esforço no trabalho (DAVIS, 1989).

\section{Inclusão do fator ecológico nos produtos tecnológicos}

Após construir este contexto de consumo tecnológico, baseado no ambiente deste mercado como um processo de integração e convergência associa-se ao desenvolvimento desta pesquisa, os atributos "verdes" integrados no processo de produção ou integração do produto, os quais demonstram uma potencialidade grande para o consumo diferenciado (CAIRNCROSS, 1992). Ao ser lançado um produto com estas características sustentáveis, as empresas entendem que estão contribuindo para esse novo paradigma de responsabilidade ecológica, podendo assim, ainda detectar as necessidades (utilitarismo) e desejos (hedonismo) desses consumidores correlacionados com o fato dos produtos tecnológicos poderem possuir também valores (atributos) "verdes" (MOTTA; ROSSI, 2005).

Com essa questão no mainstream global, a sociedade começa a ficar mais preocupada do que em tempos anteriores, porque estes compreendem que os impactos realizados pelo homem, podem causar problemas em um futuro próximo (OTTMAN, 2011). Ao possuir esta consciência ecológica, os consumidores passam a ser mais exigentes com o mercado em relação aos valores dispostos e ao ambiente mercadológico. 
O mercado atual está sendo definido pelo consumidor, com diversas alternativas para uma difusão do valor verde (JASSEN; JAGER, 2002), como o crescimento de materiais mais sustentáveis (BARBIERI, 2010; JELSMA, 2003; HEISKANEN et al., 2005), a modificação do pensamento da sociedade, por meio de apelos morais pelas mídias (JELSMA, 2003), e pelo comprometimento das empresas com um novo foco mais sustentável.

Os valores atuais de consumo além daqueles apenas verdes anteriormente discutidos, relacionados aos benefícios com a qualidade ou design, nos quais as modificações na imagem podem atrair cada vez mais um maior número de pessoas, constroem um novo perfil de consumidores verdes (AUTIO et al., 2009).

Entretanto hoje, no mercado, o produto pode ser sustentável e também bom, bonito, interessante e diferente, atendendo primeiramente as necessidades pessoais do consumidor, dado os valores sociais (status), hedônicos e/ou utilitários, e incrementando esta possessão do produto pelo fato da sustentabilidade estar inserida no dispositivo como uma integração.

Para a estimulação de difusão dos produtos verdes, segundo Jassen e Jager (2002), deverá haver uma mudança tanto do comportamento do consumidor quanto das próprias companhias com relação a identidade do produto.

Desta forma, por causa dessa difusão verde, analisa-se que os consumidores se sentem responsáveis pelo momento em que o mundo se encontra, como por exemplo, o aquecimento global (STEIN; KHARE, 2009). Logo, tomam certas atitudes para que diminuam sua culpa com relação ao ambiente contextualizado no consumo responsável, no qual, por exemplo, estes consomem menos energia e exigem que seus produtos também venham a consumir menos.

O contexto no qual esses produtos estão ou irão ser inseridos deverá ser considerado, identificando os fatores locais como a cultura e a ideologia de cada grupo. O comportamento está fortemente ligado à cultura e experiência do consumidor e a disponibilidade de produtos e serviços relacionados ao ambiente cultural pré-disposto vem a facilitar a aceitação deste consumo, para uma determinada sociedade. Contudo, a inserção de novos 
produtos inovadores no mercado com relação ao design do produto, descreve os valores culturais e desejos formais de um determinado período para uma dada sociedade. Então, visando a ideologia deste grupo, esta é definida como pensamentos característicos em comum de uma mesma comunidade, como uma visão de mundo coletiva. (SOLOMON, 2008).

Consumidores podem incrivelmente variar suas ideologias, e mudá-las com extrema facilidade, de acordo com seus discursos e práticas relacionadas aos seus valores sociais. Com isto, no campo da tecnologia são visualizadas quatro tipos de ideologias criadas por Kozinets (2007): os "Techtopian", que percebem o progresso tecnológico como supremo bem; os "Green Luddite", que vêem o desenvolvimento tecnológico como destrutivo para o meio ambiente; os "Techspressive", que percebem o prazer e sua realização como bem supremo, e as "Work Machine", que acreditam que o constante crescimento da economia é visto também como bem supremo. Logo, compreende-se neste contexto que os consumidores compram ideologias sobre as tecnologias.

Outros tipos de consumidores são definidos por Autio (2009), como "Antihero", que são aqueles que podem não compreender essa visão de preservação do meio ambiente, e acabam se tornando antiecológicos por acreditarem que estes produtos serão produzidos ou consumidos e não afetarão o meio ambiente.

\section{Método}

Definido que o objeto de análise seriam tecnologias com atributos verdes, não definimos um produto específico, mas coletamos de formas diversas conteúdos sobre produtos tecnológicos com apelo sustentável - isto poderia aumentar as contribuições oriundas de discussões sobre este tema, que é pouco debatido do ponto de vista comercial (benefícios do consumo). A razão pela qual se preferiu generalizar os produtos, contanto que estes fossem tecnológicos e com certa interação do ponto de vista da usabilidade, é a pouca informação, já citada, sobre o comportamento de consumo para produtos convergentes, levando em conta este ambiente e os atributos integrados atuais, além das correntes atu- 
alizações inovadoras do mercado, que identificam novos nichos e públicos alvos ligados a sensação de novas posses (BELK, 1988).

A importância da definição de cada produto para análise seria a de garantir que este possuísse além de uma apresentação inovadora diferenciada do mercado atual, atributos suficientes que servissem para explicar e justificar as preferências dos consumidores.

Baseado nestes dados para análise do produto, a opção metodológica da pesquisa foi a netnografia, que consiste em extrair informações de blogs/fóruns de discussões (KOZINETS, 2002), sobre um determinado tema em busca de informações. Esses blogs devem ser de alta confiabilidade, para possibilitar maior credibilidade quanto à legitimidade do comentário do consumidor participante.

O importante da netnografia sobre o ponto de vista da análise, é que este método utiliza um espaço aberto contendo discussões que envolvem satisfação / insatisfação da decisão de compra ou uso de um produto ou serviço (comportamento, desejo, necessidade e intenção). Nesta análise da aceitabilidade, é avaliada a decisão, baseada na influência dos fatores hedônicos e utilitários sobre a escolha e preferência de compra, associados à sociabilidade e aos valores integrados nesta preferência como o valor verde inserido.

A análise que utiliza a netnografia é desenvolvida com o mesmo rigor da análise etnográfica, na qual após a coleta dos dados, estes são codificados, categorizados e interpretados com comparações pela literatura para comprovar a pesquisa desenvolvida. A escolha do site de empresas ou grupos de discussão é determinada pela qualidade das discussões inicialmente interpretadas, assim como a procedência do responsável pelo site e pelas discussões.

Os sites utilizados para a pesquisa possuíam uma diversidade de informações para analisar e compreender como estes consumidores (ou categorias de consumidores) se comportam mediante o acesso a novos produtos com novas características. A tabela 1 apresenta os endereços eletrônicos dos sites utilizados, a data de coleta em cada website, a quantidade de discussões e as palavras chaves utilizadas para encontrar o site / discussão adequado.

O material utilizado foi de aproximadamente 31 páginas no formato Word, usado para interpretação dos conteúdos, dispostos em um arquivo ocupando 2/3 de cada página - o 1/3 restante é direcio- 
nado para codificação e resultados finais das categorias da pesquisa. A codificação desenvolvida segue o mesmo padrão utilizado por qualquer modelo qualitativo etnográfico, sem o acesso a softwares específicos, pelos quais o pesquisador após ler cada assunto, marca as palavras que descrevem informações, percepções e experiências, escrevendo ao lado sinônimos ou percepções deste pesquisador, sobre o participante analisado. Estes conteúdos ou palavras simples devem tender a gerar adjetivos para os contextos descritos.

Após a primeira codificação, seja esta por palavra, seja por pequenas frases, uma segunda codificação é realizada das codificações primárias e, após isto, assuntos são criados para descrever resultados que se assemelhem (categorizações).

Os tipos de enredos utilizados para análise e os pôsteres totais avaliados estão descritos na tabela 2 . Verifica-se, nesta tabela, que os pôsteres totais são aqueles relacionados ao número total de participações para cada enredo, nos quais um participante pode postar mais de uma vez seus comentários para uma mesma discussão.

Tabela 1. Dados primários da pesquisa

\begin{tabular}{l|c|c|c}
\hline Nome/URL & $\begin{array}{c}\text { Data de } \\
\text { coleta, ano } \\
\text { de } 2011\end{array}$ & $\begin{array}{c}\text { № de } \\
\text { discussões }\end{array}$ & $\begin{array}{c}\text { Palavras chaves } \\
\text { pesquisadas: }\end{array}$ \\
\hline TecMundo: http://www.tecmundo.com.br/ & $\begin{array}{c}05 \text { de dez. } \\
\text { até } 30 \text { de } \\
\text { janeiro }\end{array}$ & 5 & $\begin{array}{c}\text { Ecologia, } \\
\text { Tecnologia }\end{array}$ \\
\hline Gizmodo: http://gizmodo.com.br/ & 14 de março & 1 & Inovação \\
\hline Papel Pop: http://papelpop.com/ & 7 de abril & 1 & Moda, Desing \\
\hline Game Vício: http://www.gamevicio.com.br/ & 25 de abril & 2 & $\begin{array}{c}\text { Tecnologia, } \\
\text { Inovação }\end{array}$ \\
\hline Eco4planet: http://eco4planet.uol.com.br/ & 26 de abril & 1 & $\begin{array}{c}\text { Sustentável, } \\
\text { Ecológico }\end{array}$ \\
\hline Ambiente Brasil: http://www. & 2 de maio & 1 & $\begin{array}{c}\text { Ecologicamente } \\
\text { correto, "Legal" }\end{array}$ \\
\hline Portal G1: http://www.gl.com.br/ & 8 de abril & 1 & $\begin{array}{c}\text { Útil, Beleza, } \\
\text { Desing }\end{array}$ \\
\hline TOTAL: & & 12 & \\
\hline
\end{tabular}


Os sites utilizados foram os mais populares e acessados pelos heavy users (usuários experientes), que procuram muitas informações referentes a tecnologia, como notícias sobre o meio ambiente e moda, ficam mais atualizados e participantes sobre seus assuntos de interesse. $\mathrm{Na}$ tabela 2, são apresentados os objetos de estudo analisados que foram divididos em três tipos.

O primeiro sendo "Celular", que são produtos já existentes no mercado nacional, existindo alguns modelos lançados fora do Brasil, além dos protótipos de celulares (smartphones), em que os conceitos de valor, percepção da utilidade e predição de uso são bem discutidos nos blogs.

O segundo objeto, o "Netbook", invadiu o mercado nos últimos anos, como um produto pequeno com peso reduzido, bateria de maior duração com relação a um Notebook e, sendo basicamente, utilizado para acesso rápido de serviços de internet, como verificação de e-mail com maior acessibilidade e facilidade de uso.

O terceiro e último objeto foi descrito como "Outros dispositivos", que são outros produtos existentes no mercado como computadores ecológicos, capa-carregador solar para iPhone, impressoras, ou seja, Gadgets em geral.

A conexão da literatura de tecnologia integrada e comportamento de consumo, juntamente com a literatura de consciência verde (ideologia) e responsabilidade socioambiental, são formatadoras da justificação dos comportamentos analisados, para poder explicar como estes consumidores decidem e que valores criam um cenário mais propício para a aceitação destes produtos verdes.

As categorizações são como pontos que determinam uma pesquisa qualitativa na área de marketing e são estratégias para identificar o tipo de consumidor e interpretar suas necessidades ou desejos por meio do tipo de público alvo. Baseado nos dados descritos anteriormente e nas informações coletadas nos sites de discussões sobre produtos tecnológicos verdes descrevem-se a seguir as categorias identificadas. 
Tabela 2. Divisão do Enredo Desenvolvido para dar Suporte à Pesquisa.

\begin{tabular}{|c|c|c|c|c|}
\hline Objeto & Nome do enredo & Título das discussões & $\begin{array}{c}\text { № de } \\
\text { pôsteres } \\
\text { totais }\end{array}$ & Palavras \\
\hline \multirow{3}{*}{ Celular } & $\begin{array}{l}\text { Surpresos com a } \\
\text { tecnologia }\end{array}$ & $\begin{array}{c}\text { Conceito de celular } \\
\text { ecológico fica transparente } \\
\text { conforme a bateria acaba. } \\
\text { Celular de madeira: } \\
\text { ecologia nas suas mãos. } \\
\text { Novos eletrônicos: } \\
\text { Motorola A45 Eco } \\
\text { "Motocubo". }\end{array}$ & $\begin{array}{l}31 \\
34 \\
17\end{array}$ & $\begin{array}{l}811 \\
845 \\
1026\end{array}$ \\
\hline & $\begin{array}{l}\text { Em busca de } \\
\text { informação }\end{array}$ & $\begin{array}{c}\text { Puma Phone: o celular } \\
\text { ecologicamente correto. } \\
\text { Celular já vem com painel } \\
\text { solar. } \\
\text { O celular verde Samsung } \\
\text { Reclaim é azul e feito de } \\
\text { milho (Updated!). }\end{array}$ & $\begin{array}{l}15 \\
21 \\
42\end{array}$ & $\begin{array}{l}528 \\
544 \\
778\end{array}$ \\
\hline & $\begin{array}{l}\text { Utilidade } \\
\text { vs. beleza }\end{array}$ & $\begin{array}{c}\text { Puma lança celular com } \\
\text { carregador solar em } \\
\text { Barcelona. } \\
\text { Eu quero um Motocubo! } \\
\text { Blue Earth - O celular } \\
\text { Ecológico da Samsung }\end{array}$ & $\begin{array}{l}19 \\
28 \\
19\end{array}$ & $\begin{array}{r}223 \\
878 \\
1395\end{array}$ \\
\hline Netbook & $\begin{array}{l}\text { Avaliando o } \\
\text { produto }\end{array}$ & $\begin{array}{c}\text { Made in Brazil Sony lança } \\
\text { netbook ecológico no } \\
\text { Brasil. } \\
\text { Sony lança netbook } \\
\text { 'ecológico', feito com } \\
\text { plástico reciclado de CDs } \\
\text { e DVDs. } \\
\end{array}$ & 31 & 713 \\
\hline $\begin{array}{c}\text { Outros } \\
\text { dispositivos }\end{array}$ & Desejo de compra & Tecnologia Verde. & 14 & 700 \\
\hline TOTAL & & & 273 & 8876 \\
\hline
\end{tabular}




\section{Análise da percepção dos consumidores tecnológicos com o fator ecológico}

Após a análise dos dados coletados, foram categorizados seis grupos distintos de consumidores com algumas subcategorias implícitas. Cada uma destas categorias é apresentada constando de uma breve descrição sobre o posicionamento e situação do grupo inserido na corrente categoria, seguido das discussões principais dos consumidores analisados, as quais possuem a página e linha na qual foram retiradas as escritas do banco de dados e, finaliza-se com o cruzamento da literatura e interpretação dos autores sobre os comentários que distinguem categoricamente estes consumidores.

\section{Preferências de uso hedônico e justificação utilitária sustentável}

Na categoria, a preferência de uso mostra como consumidores de tecnologias se vêem diante de uma compra que tem o fator ecológico envolvido. Os hedonistas que prezam pela diversão, tentam justificar o item sendo ecologicamente correto, apresentando a utilidade deste como explicação para o uso. Solomon (2008), afirma que a ecologia é a forma pela qual um sistema se encaixa no seu ambiente, logo, quanto mais facilidade de uso e utilidade mais justificável apresenta-se o produto.

se eu tivesse um desses faria até a 'São Silvestre' ouvindo mp3, navegando na net, sabendo minha velocidade e brincando com o dylan lógico $\wedge \widehat{\wedge}$ p. 17 ; linhas 5-6.

Adorei pois tem aplicativo para facebook, e last.fm e também é ECOLOGICAMENTE CORRETO p. 7; linhas 54-55.

eu comprei um, e acho o aparelho muito útil, até porque tem o messenger, orkut, myspace entre outros. p.9; linhas 21-23.

Pelos comentários dos consumidores, percebe-se que estes são posicionados como hedônicos. Os produtos que eles estão comentando são celulares como o "Motocubo" e o "Puma Phone", sendo que o primeiro tem atalhos para aplicativos para redes sociais, e 
o segundo é focado ao público esportivo. Em um dos comentários sobre participar da mais popular e concorrida realização de esporte de rua (corrida), a "São Silvestre", o consumidor informa a importância do uso deste produto na corrida, só para usar o celular enquanto faz o percurso, posicionando-se como um usuário de diversão, o qual foca nos atributos hedônicos mesmo quando este celular possui o apelo verde.

É possível visualizar que há uma preferência por itens hedônicos, dado a preferência principal dos usuários, e como todos estes dispositivos atuais são integrados possuindo multifuncionalidade, acabam por ter uma maior facilidade de justificação do seu uso, dado o fator utilitário que este também normalmente possui. No caso do apelo verde, o fator utilitário é o ecologicamente correto, que serve como proteção para explicar a razão de comprar, usar e em geral, possuir um produto focado à diversão.

Com isto um novo conceito de utilitarismo é desenvolvido, denominando-se de utilitarismo sustentável, o qual distingue o usuário responsável socialmente do posicionado pelo status social. Desta forma, a dificuldade de analisar se o consumidor é utilitário sustentável (responsável social) ou posicionado socialmente (buscando status pelo uso diferenciado do produto) é grande, já que o consumidor justifica sua escolha dado o sentimento de culpa. A responsabilidade social e/ou ambiental é vista neste momento como uma utilidade para a sociedade, pois os consumidores buscam produtos que são úteis não somente para eles, mas toda uma sociedade (HEISKANEN et al., 2005; JASSEN; JAGER, 2002).

\section{Consumidor verde}

Os consumidores verdes têm a preocupação com o meio ambiente e compram para um mundo melhor. Bem informados, não consomem menos, mas apenas diferentemente. Preferem produtos que contribuam de alguma forma para a causa ambiental. Com estas referências do tipo de consumidor verde, nota-se, na análise de dados, duas subcategorias de consumidores verdes:

a) Orientados pela responsabilidade social - possuem interesses voltados ao meio ambiente pela razão do sentimento de 
culpa que esta causa provoca (ambiente poluído). O marketing verde estimula esse tipo de pensamento entre os consumidores, incentivando as compras por produtos verdes para justificar a aceitação e adoção.

Sou eng $\underline{\text { a }}$ ambiental, e essas coisas só eram promessas há 10 anos atrás. Hoje, temos a oportunidade de comprar - mesmo que seja mais caro, pois vai faltar wall-e para cuidar do e-waste que geramos!!! p. 13; linhas 26-30

E eu sei que vão me apedrejar mas, desta vez, não achei caro. Tá, você acha um com a mesma configuração por 1500 reais de outras marcas, mas eles não são feitos de cds e garrafas pet. $O$ preço não é pela configuração, é pelo que ele traz de diferente. p. 14; linhas 15-19

Sinceramente, o celular pode ter seus defeitos, mas gostei... Li os comentários e percebi que muitos gostariam que tivesse wi-fi. Mas no mundo em que estamos vivendo não importa só o wi-fi, mas importa o meio ambiente. p. 9; linhas 50-54

Identifica-se, nestes usuários, que a construção pessoal de uma cultura com ideologia verde, para prezar pelos valores pró-ecologia, acaba categorizando suas necessidades para um grupo com senso comum diferenciado, e estes, buscam práticas que normalmente não são entendidas por outros usuários, dado o contexto comum inexistente e também a falta de informação com práticas diárias, que são desconhecidas pela maioria da população em geral (OTTMAN, 2011; HEISKANEN et al., 2005). Os comentários anteriores estão relacionados ao netbook "Sony Vaio W Eco" feito de material reciclado e o celular "Puma Phone".

b) Orientados pelo prestígio social - têm seu interesse voltado ao mundo exterior, usam a moda ecológica como uma forma para se sobressair sobre os demais. São consumidores hedonistas que se valem da justificativa do ecológico para justificar suas compras e ânsia de obter o produto (BELK, 1988).

Assim q chegar no Brasil ja vou comprar! p. 20; linha 21.

Perfeito!!! são iniciativas assim que fazem a diferença que unem tecnologia e ecologia. Pena realmente apenas não passar de um telefone conceito, bem que poderia ser uma pretensão de realidade de futuro breve. p. 2; linhas 24-28. 
Gostei. É bonitinho, azul, "inteligente”, e quase ecologicamente correto é só tirar a embalagem. Ano que vem eu troco por esse. - p-20, linhas 26-29.

$\mathrm{d}+$ esse celular é tudo d bom, barato, ecológico e moderno quem não iria querer comprar um desse. p-20, linhas 32-34

Percebe-se que a ideologia dos Techspressive defendida por Kozinets (2007) é frequente para os consumidores verdes que são hedonistas. Avalia-se ainda a ânsia por ter o produto, de forma a aumentar rapidamente seu prestígio social devido ao marketing social destes produtos, que acabam por influenciar as ações e modo de pensar, além do modo de agir de seus consumidores (SOLOMON, 2008). Os comentários acima referem-se ao celular Reclaim da Samsung, e o conceito de celular desenvolvido pelos designers Cho Sinhyung e Jeon Jungjae.

Como o consumidor não possui uma predição de uso bem definida (NUNES, 2000), um maior número de integrações desenvolve um processo de decisão facilitado e bem aceito pelo usuário. As características diferenciadas das convencionais também são pontos fortes de diferenciação do uso e possessão (ex. carregador solar ou materiais reciclados). Assim, os consumidores acreditam que por se tratar de uma causa social (ajudar o meio ambiente) terá um retorno com um prestígio social maior e será bem visto pelos demais.

c) Percepção de risco - $\bigcirc$ consumidor constrói uma percepção de risco antes da aquisição do produto de acordo com as informações adquiridas por ele (ENGEL; BLACKWELL; MINIARD, 2000; SOLOMON, 2008). Este risco percebido é definido como uma crença sobre um produto no qual trará implicações negativas posteriormente. Dado o uso atual dos produtos verdes / sustentáveis serem baixos - o número de boas relações individuais e redes de comunicações alcançam poucos usuários dentre outros, gerando uma identidade ainda fraca para o valor verde ser reconhecido no Brasil. Isto dificulta uma percepção positiva para dar sustentabilidade ao produto do ponto de vista mercadológico.

Um celular desses tem de por no seguro, porque de tão frágil que vai ser. p. 2, linhas $44-45$ 
Display touchscreen no sol? :S não vai dar muito certo. p. 24, linhas 16-17

a ideia é boa! mas será que funciona do jeito que deveria? eu tenho o Blue earth da Samsung, eu tava mó animado com essa de carregador solar, mas ele demora umas 2 horas pra recarregar apenas um traço da bateria, espero que esse da Puma funcione melhor. p. 24, linhas 16-17

Consumidores brasileiros demonstraram apreensão e até um preconceito sobre os produtos integrados verdes, pois por mais que Harris e Blair (2006) afirmem que quanto maior o número de integrações menor o risco, o fator verde integrado transfere percepções negativas que contaminam a percepção geral do produto. Como a experiência nacional é ainda baixa para produtos neste contexto, a robustez é vista como precária gerando desconfiança e fragilidade para a aceitação no mercado.

d) Antiecológicos irônicos - Nesta categoria apresenta-se o consumidor que discorda do discurso verde, se aproximando da ideologia dos "Green Luddites", definida por Kozinets (2007). Esta corrente apresenta que o desenvolvimento tecnológico é destrutivo para o meio ambiente não importando a necessidade, além dos "Antiheros" (AUTIO, 2009) que crêem que tudo não passa de uma propaganda falsa, e que não lhe trará qualquer tipo de benefício. Os consumidores desta categoria estão interessados em consumir mais, suprir suas necessidades hedonistas da forma mais prazerosa e não se importar com a "falsidade ecológica".

"Os cupins aqui de casa agradecem ..." P. 4, Linha 39

E ainda tem gente q compra! p. 22, linha 49

Ecochatos teriam motivo para comprar um desses, só não teriam dinheiro para um. p. 14, linhas 35-36

Ainda prefiro celulares com materiais plásticos do que madeira, porque duvido que essa empresa irá replantar todas as árvores usadas para cada celular lançado. p. 4 linhas 46-49

Este tipo de consumidor é parte de um grupo de usuários irônicos expressando o sentimento reverso sobre as atitudes eco- 
logicamente corretas, informando que o contexto não passa de ações falsas e sem sentido sobre uma realidade de protecionismo e mercado (AUTIO et al., 2009). O conceito desenvolvido do celular MINIMA é criticado por possuir a carcaça de madeira, por isso a ironia relacionada aos cupins. Logo, estes consumidores também comentam sobre o netbook Sony Vaio W Eco, como se fosse algo dispendioso.

Descrentes da ideologia dos consumidores verdes, estes os intitularam como "ecochatos", por acharem que uma pequena mudança não fará diferença alguma do ponto de vista global. Posicionam-se como um grupo social, o qual percebe todo o pensamento sobre o assunto, como sendo chato, assim como qualquer tipo de informação disseminada com a finalidade de promover o meio ambiente.

e) Preocupação com o benefício (percepção) - demonstra-se preocupada com o preço dos produtos (SOLOMON, 2008), e tendem a comparar valores com a concorrência em geral, mesmo não sendo sustentável, para avaliar se o benefício do produto verde, vale a diferença de custo para o consumo. Por mais que a literatura informe que o preço é uma medida de qualidade, na qual altos valores indicam produtos com alta qualidade (BRUCKS; ZEITHALM; NAYLOR, 2000), o consumidor verde precisa de outros valores para se beneficiar de um produto verde.

O produto não pode apenas possuir o apelo verde, pois precisa de valores sociais e hedônicos que os estimule a serem comprados - o apelo verde é um extra ao produto. Quando o produto é focado no seu valor sustentável, não importando o quanto seja ecologicamente correto, este está fadado a falhar no mercado quando percebido como caro ou dispendioso. Alguns autores apontam que o consumo desses produtos é elitizado e é viável apenas para uma pequena parte da sociedade (PAAVOLA, 2001). O produto abaixo comentado é o netbook Sony Vaio W Eco.

nossa, carinho, hein? onde está aquele espírito ONG sem fins lucrativos agora? p. 13, linhas 39-41

ABSURDO! Usar material reciclável, mais barato, e usar mão de obra a menos de dólar por dia e ainda cobrar isso tudo. Onde o mundo vai parar? p. 19, linhas 33-35 
Mas o valor com certeza será bem alto. $\mathrm{O}$ fato de possuir tecnologia ecológica encarece o produto e isso ta erradíssimo! p. 11, linhas 25-27

pois é, esse net pode respeitar a natureza, mas para o meu bolso ele é muito mal educado! p. 13, linhas 12-13

Existe público alvo para os produtos verdes, mas estes precisam possuir um valor mercadológico mais aproximado dos concorrentes ou substitutos de mercado, ou ainda, focar em valores de desejo de consumo, para que a compra seja feita pelos atributos hedônicos / sociais que possivelmente irão requerer a justificação utilitária. Para Prahalad (apud CARVALHO; MOZONI, 2001), algumas empresas percebem que a questão ambiental / sustentável poderá causar danos à sua produtividade e competitividade, assim colocam estes fatores em standby, para tratar desta necessidade como responsabilidade social, ou seja, oposto aos objetivos do negócio, apenas com um pequeno modelo ou plano institucional para a imagem da empresa.

f) Inovadores - são os consumidores que se atraem pelas inovações dos produtos, gerando uma alta expectativa para a compra, como uma ânsia de obter o produto mais rápido que os demais consumidores. Estes usuários estão sempre conectados à rede e as notícias sobre novos produtos, têm um vasto conhecimento sobre eles e normalmente conhecem bem sobre tecnologia. Como são os iniciantes da aceitação de um novo produto, são também os que influenciam a opinião pública e a mídia dos novos produtos. Neste estudo, a categoria de inovadores foi sub-categorizada em outros dois grupos de usuários.

- Orientados pelo prestígio social - estão mais interessados em como esses produtos farão uma auto-referência dele, posicionando-os para a sociedade que os vê. Percebem as inovações em um sentido que os mostrem como uma extensão do eu (BELK, 1988; SOLOMON, 2008). Fatores como design impulsionam a compra e preferência por esses produtos, pois é importante ser diferenciado e atualizado com relação aos demais consumidores (KATZ; SUGIYAMA, 2006; GEMSER; JACOBS; CATE, 2007). 
Os produtos abaixo que foram comentados foram o Motocubo e o Puma Phone, focando o conceito de celular ecológico. A necessidade de apresentar-se para a sociedade, tendo prazer e satisfação em compartilhar com os demais sua posse, é o que define prioritariamente este grupo. Estes consumidores preferem o design e a cor do produto, assim como a forma, a marca, a moda, dentre outros que gerem valor social, mas sem desconsiderar a tecnologia, pois estar mais atualizado que os outros também é status social (ARRUDA FILHO et al., 2008). O que importa para esses consumidores é ser visto com a mais bela e avançada tecnologia existente, o fator ecológico é só mais uma integração ou integração ao modismo.

Um novo e genial conceito para tecnologia de celulares provavelmente serão assim os celulares do futuro. E esse será o meu futuro celular $\mathrm{xd}$ p. 3, linhas 46-48

Realmente! A única coisa que me atraiu foi o design porque sem touch, sem Wi-fi ou $3 g$ "ele não é ninguém". Mas esse laranja é tentador!!!

p. 24, linhas 27-29'

Será que ele e sensível como a função "shake" do Iphone?? Pq se for é um Ótimo concorrente $=$ D p. 24, linhas 26-29

- Orientados pela tecnologia - Usuários da ideologia dos "Techspressive" são os mais frequentes nessa categoria, pois valorizam a qualidade e a novidade do produto, portando até ao prazer do uso pela tecnologia. São os nerds, geeks, e outras denominações dadas para os consumidores high tech, os quais estão conectados todo o tempo em busca de novidades e inovações dentro dos dispositivos de interesse. Estes usuários são extremamente informados, conhecedores da tecnologia, dos concorrentes e dos novos lançamentos que virão. Buscam validar suas compras e decisões, focando na qualidade do produto e suas integrações. $\bigcirc$ fator ecológico não é o maior dos interesses deste grupo, e sim, a tecnologia em si mesmo. Caso a tecnologia seja focada ao sustentável, talvez eles valorizem a integração disto. $\mathrm{O}$ que o produto tem pra mostrar de melhor e mais inovador é o que conta e o que o diferencia no mercado (NUNES et al, 2000). 
em vez de tomar vergonha na cara e desenvolver um celular que presta ela lança um com tecnologia obsoleta! fala sério, sem wi-fi e sem $3 g$ ? pfff... Meu celular tem teclado QWERTY, wi-fi, 3g, câmera com flash, bluetooth AD2P e muito mais" p. 8, linhas 32-37

Gostei do estilo, espero que saia logo, não vejo a hora! Em questão de funcionalidade, se eles usarem o ANDROID, como leva a parecer na foto do concept, vai ser a fome e a vontade de comer!!! p. 1-2, linhas 42-3

o target da Moto é o jovem, não usuários mais experientes como nós que caçam reviews de celular. se vai ser moda como o V3?! VAI, sim, senhor!" p. 8-9, linhas $54-2$

\section{Considerações finais}

Este artigo baseia-se na análise de consumo de produtos tecnológicos com integração verde presentes no mercado atual (celulares e netbooks) e alguns que ainda estão sendo desenvolvidos no decorrer do período (conceitos). Estes produtos são providos cada vez mais de integrações que são consideradas hedônicas, como MP3 player (música), câmeras fotográficas e vídeos com utilização do formato $\mathrm{mp} 4$, entre tantos outros serviços integrados simultaneamente (FUNK, 2004). Com o apelo ecológico, diversos produtos apresentam portando um menor impacto ambiental ao mercado, ou com materiais sustentáveis feitos de restos de CDs, de madeira, com carregadores solar etc. (BARBIERI, 2010; OTTMAN 2011), os quais foram escolhidos como objetos principais de estudo para a pesquisa.

Com isto foi analisado se a motivação de compra para a tecnologia é ligada ao próprio apelo verde ou a outros fatores como o design, inovação e o valor social inseridos no dispositivo. Também é analisada a percepção de risco, crença em propagandas falsas e identidade do valor verde inserido à tecnologia. Entendemos que existem diferentes tipos de consumidores verdes, sensibilizados de alguma forma pela ideologia sustentável, gerando uma diversidade de categorias de consumo.

Estas categorias encontradas desenvolvem resultados importantes para lançamento de produtos, desenvolvimento de novos dispositivos, percepção de valores de mercado, promoções e outros 
para melhor entender o público alvo e sua preferência de consumo. Estas categorias também descrevem um pouco da cultura nacional. Logo, identifica-se que existe uma grande parte hedônica de consumidores, buscando prazer e satisfação em sua compra e uso, porém, justificando sua compra pelo uso utilitário dado a culpa intrínseca com altos custos e gastos para diversão.

Outros consumidores estão em busca de valor social e diferenciação no mercado, apresentando que existe o valor ecológico no produto, mas que este seja também bonito e da moda. Para aqueles que possuem uma grande percepção de risco com a compra de produtos verdes, cenário no qual o apelo principal do produto é a sustentabilidade e não algo integrado a ele, o dispositivo perde robustez de mercado. Então, analisa-se que pode ser possível uma ampliação de um mercado nacional para produtos verdes / sustentáveis, porém, estes terão que ter como primazia a diferenciação do produto com valores hedônicos, sociais, ligados a moda.

Outro grupo de consumidores ainda percebe o lado ambiental como uma fachada sem resultado útil. Por falta de mercado no setor ecológico e falta de identidade nacional, isto ainda é bastante encontrado em um público pouco informado, deixando assim um nicho a ser trabalhado. O problema principal encontrado é para consumidores com percepção de desperdício, pois quando o valor do produto é caracterizado diretamente pelo seu preço, sendo este considerado alto, o produto desvaloriza ainda mais sua identidade.

Finaliza-se a pesquisa dos consumidores para produtos tecnológicos verdes, com os inovadores que possuem busca pelo mais atual e mais moderno, sendo estes focados para o social ou para a atualização tecnológica. Baseado nisto, têm-se o mesmo tipo de consumidores tecnológicos comuns, que apenas utilizam do produto com apelo verde como uma desculpa utilitária que justifique o uso deste, ou um pequeno grupo de idealistas sobre a preservação ambiental.

Como a pesquisa foi realizada em meio virtual, teve limitações para encontrar discussões suficientes que analisassem os produtos de mercado. É percebido pelo estudo, que por ser um conceito de produto ainda pouco familiar ao consumidor, existe certo preconceito sobre os produtos e uma carência no mercado, sobre o que 
pode servir de motivação para se investir nestes. Com as análises dos dados, foi percebido que o consumidor anseia esses produtos, mas não tem acesso ou informações suficientes para consegui-los. Logo, é necessária uma difusão maior da ideologia ambiental, além de por em prática a responsabilidade social das pessoas e das empresas, para que se atinja uma sociedade sustentável.

\section{Referências}

ARRUDA FILHO, Emílio José Montero. Incluindo o fator social no modelo de aceitação tecnológica para estruturas convergentes. Revista de Administração - RAUSP, São Paulo, v.43, n.4, p. 315-330, 2008.

ARRUDA FILHO, Emílio J. M.; CABUSAS, Julianne Joy e DHOLAKIA, Nikhilesh. Fator social versus tecnologia utilitária: marketing social versus mercado utilitário Revista de Gestão da Tecnologia e Sistemas de Informação, São Paulo, v. 5, n. 2, p.305-324, 2008.

AUTIO, Minna; HEISKANEN, Eva; HEINONEN1, Visa. Narratives of 'green' consumers: the antihero, the environmental hero and the anarchist. Journal of Consumer Behaviour, Hoboken, v. 8, n. 1, p.40-53, jan. 2009.

BARBIERI, J. C.; VASCONCELOS, I. F.; ANDREASSI, T.; VASCONCELOS, F. C. de. Inovação e sustentabilidade: novos modelos e proposições. Revista de Administração de Empresas - RAE, São Paulo, v. 50, n. 2. p. 146-154, 2010.

BEDANTE, Gabriel Navarro. A influência da consciência ambiental e das atitudes em relação ao consumo sustentável na intenção de compra de produtos ecologicamente embalados. 2004. 159 f. Dissertação (Mestrado em Administração) - Universidade Federal do Rio Grande do Sul.

BELK, R. W. Possessions and the Extended Self, Journal of Consumer Research, Chicago, v. 15, n. 2 p.139-168, set. 1988.

BERTOLINI, G. R. F.; POSSAMAI, O. Proposta de instrumento de mensuração do grau de consciência ambiental, do consumo ecológico e dos critérios de compra dos consumidores. Revista de Ciência e Tecnologia, Piracicaba, v.13, n. 25-26, p. 17-25, 2005.

BRUCKS, Merrie; ZEITHALM, Valarie A.; NAYLOR, Gillian. Price and brand name as indicators of quality dimensions for consumer durables. Journal of the Academy of Marketing Science, Eat Lansing, v. 28, n.3, p. 359-374. 
CAIRNCROSS, Frances. Meio ambiente: custos e benefícios. São Paulo: Nobel, 1992.

CARVALHO, André; MONZONI; Mario. Sustentabilidade só um modismo. GV Executivo, São Paulo, v. 9, n.1, p.44-47, 2010.

DAHL, D. W.; HONEA, H.; MANCHANDA; R. V. Three rs of interpersonal consumer guilt: relationship, reciprocity, reparation. Journal of Consumer Psychology. [s.1.], v. 15, n. 4, p.307-315, 2005.

DAHL, D. W; HOEFFLER, S. Visualizing the self: exploring the potential benefits and drawbacks for new product evaluation. Journal of Product Innovation Management, [s.1.], v. 21, n. 4, p.259-267, 2004.

ENGEL, J. F.; BLACKWELL, R. D; MINIARD, P. W. Comportamento do consumidor. 8.ed. Rio de Janeiro: Ltc, 2000.

FLICK, Uwe. Desenho na pesquisa qualitativa. Porto Alegre: Artmed, 2009.

FUNK, Jeffrey L. Key technological trajectories and the expansion of mobile Internet applications. The Journal of Policy, Regulation and Strategy for Telecommunications, Information and Media, Tokyo, v. 6, n. 3, p.208-215, 2004.

GEMSER, G.; JACOBS, D.; CATE, R. Ten. Design and competitive advantage in technology-driven sectors: the role of usability and aesthetics in Dutch it companies. Technology Analysis \& Strategic Management, London, v. 18, n. 5, p.561-580, dez. 2006.

HARRIS, J.,BLAIR, E. A. Functional compatibility risk and consumer preference for product bundles, Journal of the Academy of Marketing Science, East Lansing, v. 34, n. 1, p.19-26, 2006.

HEISKANEN, E.; KASANEN, P.; TIMONEN, P. Consumer participation in sustainable technology development. International Journal of Consumer Studies, Hoboken, v. 29, n. 2, p.98-107, 2005.

HOCH, S.T.; DEIGHTON, J. Managing what consumers learn from experience. The Journal of Marketing, Chicago, v. 53, n. 2, p. 1-20, abr. 1989.

HOEFFLER, S. Measuring preferences for really new products. Journal of Marketing Research, Chicago, v. 40, n. 4, p. 406-420, 2003.

JANSSEN, Marco A.; JAGER, Wander. Stimulating diffusion of green products, Journal of Evolutionary Economics, Heidelberg, v. 12, n. 3, p. 283306, 2002. 
JELSMA, J. Innovating for sustainability: involving users, politics and technology. Innovation: The European Journal of Social Sciences, London, v. 16, n. 2, p.103-116, 2003.

KATZ, J. E.; SUGIYAMA, S. Mobile phones as fashion statements: evidence from student surveys in the US and Japan. New Media and Society, Vancouver, v. 8, n. 2, p.321-337, abr. 2006.

KIM, Y. ; LEE, J.; KOH, D. Effects of consumer preferences on the convergence of mobile telecommunications devices. Applied Economics, Londres, v. 37, n.7, p.817-826, abr. 2005.

KOZINETS, Robert V . The Field Behind the Screen: Using netnography for marketing research in online communities. Journal of Marketing Research, Chicago, v. 39, n. 1, p. 61-72, fev. 2002.

KOZINETS, Robert V. Technology/ideology: how ideological fields influence consumers' technology narratives. Journal of Consumer Research, Chicago, v. 34, n.6, p.865-881, 2007.

MOTTA, S. L. S; ROSSI, G. B. Influência do fator ecológico na decisão de compra de bens de conveniência. Revista de Administração Mackenzie RAM, São Paulo, v. 2, n. 2, p.109-130, 2008.

NUNES, J. C. A cognitive model of people's usage estimation. Journal of Marketing Research, Chicago, v. 37, n. 4, p.397-409, nov. 2000.

NUNES, P.; WILSON, D.; KAMBIL A. The all-in-one market. Harvard Business Review. [s.1.], v. 78, n. 3, p. 397-409, maio 2000.

OKADA, E. M. Justification effects on consumer choice of hedonic and utilitarian goods. Journal of Marketing Research, Chicago, v. 42, n .1, p. 43, 2005.

OTTMAN, Jacquelyn. The new rules of green marketing: strategies, tools, and inspiration for sustainable branding. São Francisco: Berrett Koehler - BK, 2011.

PAAVOLA, J. Economics, ethics and green consumerism. In: COHEN, M. \& MURPHY, J. (eds.). Exploring sustainable consumption: environmental policy ant the social sciences. Oxford, Elsevier Science, 2001. p.79-96.

PORTILHO, Fátima. Consumo verde, consumo sustentável e a ambientalização dos consumidores. In: 2 ํㅡㄹ ENCONTRO DA ANPPAS, 26 a 29/05/2004, Indaiatuba, 2004. 21p.

ROGERS, E. M. Diffusion of innovations. 5.ed. Nova York: Free Press, 2003. 
SANCHES, Carmem S. Gestão Ambiental Proativa. Revista de Administração de Empresas - Rae, São Paulo, v. 40, p.76-87, 2000.

SOLOMON, Michael R. O comportamento do consumidor: comprando, possuindo e sendo. 7.ed. Porto Alegre: Bookman, 2008.

STEIN, M.; KHARE, A. calculating the carbon footprint of a chemical plant: a case study of Akzonobel. Journal of Environmental Assessment Policy and Management, [s.1.], v. 11, p.291-310, 2009.

STEPHEN, A.T., TOUBIA, O. Deriving value from social commerce networks. Journal of Marketing Research, Chicago, v. 47, p.215-228, 2010.

Recebido em: 5.12.2011 Aceito em: 17.4.2012 